\section{ASSOCIATIONS BETWEEN MATERNAL TRANS ISOMERS AND CORD BLOOD POLYUNSATURATED FATTY ACIDS AT BIRTH}

T. Marosvölgyi ${ }^{1}$, É. Szabó ${ }^{1}$, C. Campoy ${ }^{2}$, B. Koletzko ${ }^{3}$, T. Decsi ${ }^{1}$

${ }^{1}$ Department of Paediatrics, University of Pecs, Pecs, Hungary, ${ }^{2}$ Department of Paediatrics, University of Granada, Granada, Spain, ${ }^{3} D r$. von Hauner Childrens' Hospital, University of Munich, Munich, Germany

Background and aims: Trans isomers may disturb the metabolism of $n-3$ and $n-6$ polyunsaturated fatty acids (PUFAs), so our aim was to investigate whether maternal trans fatty acid status is associated to the cord blood PUFA supply.

Methods: Expecting mothers were supplemented with either fish oil ( $\mathrm{FO}, \mathrm{n}=36$ ) or with 5-methyltetrahydro folic acid (5-MTHF, $n=25)$ or both (FO+5MTHF, $n=34)$ or placebo $(n=30)$ from the 20 th week of gestation onwards. The fatty acid composition of erythrocyte membrane phosphatidylethanolamine lipids of maternal blood at delivery and cord blood was determined with gas chromatography.

Results: There were no significant correlations between maternal $\mathrm{C} 18: 1 \mathrm{n}-7 / 9 \mathrm{t}$ and cord blood C18:2n-6 and C20:4n-6 values in the four supplementation groups. In contrast, we found significant inverse correlations between maternal C18:1n-7/9t and C22:5n-3 values in the cord blood in all supplementation groups (table). The values of maternal C18:1n-7/9t correlated significantly and inversely to cord blood $\mathrm{C} 22: 6 \mathrm{n}-3$ in the $\mathrm{FO}$ and FO+5-MTHF groups (table).

\begin{tabular}{|l|l|l|l|l|}
\hline $\begin{array}{l}\text { C18:1n- } \\
7 / 9 t\end{array}$ & $\begin{array}{l}\text { FO } \\
(n=36)\end{array}$ & $\begin{array}{l}\text { FO+5- } \\
\text { MTHF } \\
(n=34)\end{array}$ & $\begin{array}{l}5-M T H F \\
(n=25)\end{array}$ & $\begin{array}{l}\text { Placebo } \\
(n=30)\end{array}$ \\
\hline C20:4n-6 & -0.16 & -0.08 & +0.06 & -0.23 \\
\hline C22:5n-3 & $-0.52 b$ & $-0.37 a$ & $-0.69 c$ & $-0.49 b$ \\
\hline C22:6n-3 & $-0.49 b$ & $-0.42 a$ & -0.25 & -0.21 \\
\hline
\end{tabular}

[Table]

$\mathrm{a}=\mathrm{p}<0.05,{ }^{b}=p<0.01,{ }^{c}=p<0.001$

Conclusion: Because maternal trans fatty acids correlated inversely to cord blood $n-3$, but not to $n-6$ PUFAs, we speculate that maternal trans isomers may adversely effect n-3 PUFA supply to the fetus.

\section{EVALUATION OF FAT AND NITROGEN FAECAL LOSSES IN AGA AND SGA PRETERM NEWBORNS}

L. Corvaglia, M. De Giorgi, E. Mariani, M. Spinelli, E. Legnani, G. Faldella

Neonatology and Neonatal Intensive Care Unit S. Orsola-Malpighi Hospital - University of Bologna, Bologna, Italy

Background and aims: In preterm newborns an adequate nutrition is important to obtain a growth pattern similar to the intrauterine one, without overloading the immature metabolic and excretive functions. The ESPGHAN guidelines for preterm enteral nutrition recommend to aim at $3.5-4.5 \mathrm{~g} / \mathrm{kg} /$ day protein and 4.8-6.6 g/kg/day fat enteral intake, with no distinction between AGA and SGA infants.

Our aim was to evaluate faecal fat and nitrogen losses in preterm infants, highlighting differences between AGA and SGA infants in order to optimize their fat and protein enteral intake.

Materials and Methods: Faecal fat and nitrogen content was measured at 15 days of life by NIRA (Near-Infrared-Reflectance-Analysis) in 49 preterm infants (GA< 32 wks; 33 AGA and 16 SGA) hospitalized in our NICU. Differences between AGA and SGA newborns in faecal fat and nitrogen content were evaluated by independent samples $t$ test.

Results: Faecal fat content ( $\mathrm{g} / 100 \mathrm{~g}$ of stools) was significantly higher $(p=0.043)$ in SGA infants (mean 15.65 [SD 2.36]) than in AGA (mean 13.76 [3.24]); furthermore, SGA had a higher faecal nitrogen excretion ( $\mathrm{g} / 100 \mathrm{~g}$ of stools) than AGA (1.09 [0.24] vs 0.95 [0.18], $p=0.036)$.

Conclusions: Given these data, we believe to be useful to optimize fat and protein enteral intake for preterm SGA infants according to their ability to retain ingested macronutrients, which is different from AGA.

For this reason, this study will be further developed in order to evaluate the relationship between protein and fat intake and either urinary and faecal losses in these two populations of preterm infants. 